\title{
The concept of success in representing codependent women: transformation in the conditions of the COVID-19 pandemic threat
}

\author{
Anastasia Kolenova ${ }^{1 *}$, Anna Kukulyar $^{1}$, Zinaida Brizhak $^{2}$, and Natalya Bessonova ${ }^{1}$ \\ ${ }^{1}$ Don State Technical University, 344000, Rostov-on-Don, Russia \\ ${ }^{2}$ Rostov State Medical University; Department of «Medical Law», 344022, Rostov-on-Don, Russia
}

\begin{abstract}
The presence of codependent behavior affects many areas of life, while distorting most of the personality's beliefs. Some of the most striking distortions concern the notion of success. At the same time, in conditions of uncertainty (for example, during the COVID-19 pandemic), these changes began to be of a special nature, which can be reflected not only in the features of psychocorrectional measures, but also on the quality of life of the codependent individual as a whole.

The empirical object of the study was 167 women, aged 29-35 years, in relationships (in two study periods: "before the pandemic" and "during the pandemic"). Based on the test "Scale for measuring codependency in relationships" (L. Spann-D. Fisher, adapted by V. D. Moskalenko), the sample was divided into 2 subgroups of 47 people: women with a normal level of codependency, women with pronounced codependency.

The article shows that the level of codependency of women during the period "during a pandemic" is associated with the fear of not having enough time devoted to the family, with the fear of saving the family and with the fear of a leadership position. We found a relationship between the manifestation of codependency in women during a pandemic and an orientation toward failure. There is a relationship between pre-pandemic level of codependency in women and women's perceptions of success. The level of manifestation of codependency in women in the period "before the pandemic" has an inverse relationship associated with the fear of a lack of time devoted to the family, with the fear of a leadership position. A direct correlation was revealed between their level of codependency and dissatisfaction with their professional role. A relationship was found between the level of codependency and the orientation towards success.
\end{abstract}

\section{Introduction}

The modern transitive society, the dynamism of culture and personal value orientations leave their mark on such a socio-cultural phenomenon as success. It is one of those concepts, the life meaning of which is clearly understood by ordinary consciousness, but its psychological essence is sometimes not obvious due to the multifaceted nature of its meanings and relationships, expressed in its semantics. However, people in codependent

\footnotetext{
* Corresponding author: kolenova.nastya@ya.ru
} 
relationships tend to lack the necessary skills, resulting in dysfunctional relationships and ineffective functioning.

As a phenomenon, "codependency" has been identified in psychology relatively recently. In the general sense of the word: codependency is a constant concentration of thought on someone or something and dependence (emotional, social, sometimes physical) on a person or object. Sometimes this dependence on another person becomes a pathological condition that affects all other relationships $[2,6,16]$. The research is based on works devoted to the study of the problem of codependency of such foreign authors as M. Beatty, R. Subby, E. Larsen, Waschteiner-Cruz, E. Smith, P. Kaufman, E. Smith, B. Weinhold, E. Fromm, E. Bern, K. Rogers and others [7, 8, 9, 11, 13, 18, 19, 20].

The COVID-19 pandemic has shown that the rapid transformation of the environment is transforming human life. And this directly affects the psychological state of a person, is reflected in professional self-realization. In our time, society is characterized by the desire of people for material values and various components of comfort. This gives rise to the cult of external success, the desire to possess a significant amount of money, self-determination in professional activity and the achievement of high positions, the constant receipt of various requests, etc. Currently, the number is recognized as a measure of success [12].

Many scientists define the orientation of the individual to achieve success as an integral part of the development of the individual and society [1].

Highlighting the criteria for success, we see the following division into external and internal, the first refers to the visible achievements of a person, the second refers to the inner world of a person and how the achievement of the goal affects him. But the main criterion among all is the feeling of satisfaction with their life in general.

It is worth noting that it is the feeling of satisfaction that is deficient for a codependent person, especially given the situation of uncertainty, the attitude to this concept can change markedly for codependent individuals. In this connection, it seemed to us quite relevant to study changes in the perceptions of success among codependent women in the periods "before the pandemic" and "during the pandemic."

\section{Materials and methods}

1. Methodology "Research of ideas about successful professional activity" (O. Yu. Klochkova).

2. Methodology "Motivation of success and fear of failure" ("MUN" - AA Rean).

3. Methodology "Self-assessment of manifestations of fear of success" G.V. Turetskaya.

4. Questionnaire for identifying women's ideas about the specifics of achieving success in the professional activities of I.S. Kletsina.

5. Test "The scale of measurement of codependency in relationships" (L. Spann-D. Fisher, adapted by V. D. Moskalenko).

Mathematical treatment of the obtained empirical data included definition of average values of the studied indicators prior to and during the pandemic, as well as the procedure of assessing the statistical significance of the revealed differences.

Mathematical processing of the obtained data was carried out using statistical methods: Pearson's correlation analysis and methods for assessing the reliability of differences, the Mann-Whitney empirical coefficients $U_{\text {emp. }}$, Wilcoxon's $W$ test.

For computer processing of empirically obtained data, we used standard statistical programs: Microsoft Excel 7.0 and SPSS (version 22.0).

The empirical object of the study was 167 women, age 29-35 years old, in relationships (in two study periods: "before the pandemic" and "during pandemic "). Based on the test "Scale for measuring codependency in relationships" (L. Spann-D. Fisher, adapted by V. D. 
Moskalenko), the sample was divided into 2 subgroups of 47 people: women with a normal level of codependency, women with pronounced codependency.

\section{Results}

Using the Test for Codependency (D. Fisher, L. Spann, adaptation by V. D. Moskalenko), we assessed the level of severity of codependency among respondents in two study periods: "before the pandemic" and "during the pandemic".

In the process of processing the primary data, the entire sample of 167 respondents was conditionally divided into 3 groups. The results are presented in Table 1.

Table 1.

\begin{tabular}{|l|c|c|}
\hline \multicolumn{1}{|c|}{ Codependency level } & $\begin{array}{c}\text { \% of respondents in the } \\
\text { pre-pandemic period }\end{array}$ & $\begin{array}{c}\text { \% of respondents during } \\
\text { "during a pandemic" }\end{array}$ \\
\hline Testing time & February 2019 & September 2020 \\
\hline Norma & 30 & 29 \\
\hline Moderate codependency & 42 & 39 \\
\hline Pronounced code pendency & 28 & 32 \\
\hline
\end{tabular}

By evaluating the values of the indicators, we can see that significant changes inlevels of manifestation of codependency, we have not found, which can tell us that codependency as a personal characteristic is not changeable during periods of emergency. At the same time, the tendencies of the manifestation of codependency among the respondents turned out to be as follows: the most pronounced is "moderately expressed codependency" - the respondents of this group tend in some situations to inadequately assess their relationships, for example, during the state of falling in love, sometimes they experience strong emotional dependence on their partner.A third of the women surveyed have a normal level of codependency - they are able to adequately assess their relationships with other people, can prioritize meeting their own and other people's needs, and build "healthy" relationships. Respondents with a normal level of codependency tend to adequately assess relationships and are able to prioritize interpersonal interactions and meet the needs of both theirs and others.

The least in the general sample is "pronounced codependency" - such women show strong physical, emotional and physical dependence on the object of codependent relationships, it is difficult for them to imagine life without an addict. At the same time, codependency is often not recognized, a woman considers such relationships to be the norm and often calls such relationships "close", "true love", etc. At the same time, it was this subgroup of subjects, due to the brightness of the manifestation of the psychological characteristics of codependent individuals, that formed a further research sample. We have identified a number of components of the concept of success: the motivation of success, the manifestation of success; ideas about the specifics of achieving success.

We carried out a comparative analysis of the data obtained using the methodology "Motivation for success and fear of failure" by A.A. Reana, the results are presented in Table 2.

Table 2. Features of the distribution of motivation for success and fear of failure among womeninperiods "before and during the pandemic"

\begin{tabular}{|c|c|c|}
\hline $\begin{array}{c}\text { Direction of achievement } \\
\text { motivation }\end{array}$ & $\begin{array}{c}\text { \% of respondents } \\
\text { in the pre- } \\
\text { pandemic period }\end{array}$ & $\begin{array}{c}\text { \% of respondents } \\
\text { during "during a } \\
\text { pandemic" }\end{array}$ \\
\hline
\end{tabular}




\begin{tabular}{|l|c|c|}
\hline Testing time & February 2019 & September 2020 \\
\hline Motivation for success & 31.2 & 67.3 \\
\hline Motivation for failure & 56.3 & 34.5 \\
\hline Motivational pole is not clearly expressed & 0.4 & 10.6 \\
\hline
\end{tabular}

Approximately equal number of respondents was distributed between motivation for success and motivation for failure, however, significant differences were found in all three indicators. Codependent women during the "pandemic" period are usually oriented towards failure. When they achieve success, they are afraid of failure, therefore they do not expect benefits for themselves, but they are afraid of condemnation and therefore strive for success. Codependent women prioritize not their desires, but their "fears".

Pre-pandemic codependent women are success-oriented. Initially, they do not think about failures, starting a business, they are guided by a positive result, they are ready to face failures, but failure does not scare them. Perhaps this is due to the fact that women in a familiar situation are less oriented towards a partner in relationships.

Table 3. Statistical criteria

\begin{tabular}{|l|c|c|c|}
\hline & $\begin{array}{c}\text { Motivation for } \\
\text { success }\end{array}$ & $\begin{array}{c}\text { Motivation } \\
\text { for failure }\end{array}$ & $\begin{array}{c}\text { Motivational pole is } \\
\text { not clearly expressed }\end{array}$ \\
\hline $\begin{array}{l}\text { Mann-Whitney empirical } \\
\text { coefficients Uemp }\end{array}$ & 298.500 & 310.000 & 262.500 \\
\hline Wilcoxon's W test & 695.500 & 710.000 & 543.500 \\
\hline Z & -.971 & -.951 & -2.162 \\
\hline $\begin{array}{l}\text { Asymptotic significance } \\
(2 \text {-sided) }\end{array}$ & 0.031 & 0.022 & 0.001 \\
\hline
\end{tabular}

The smallest number of respondents do not have a pronounced motivational pole, however, a much larger number of codependent women in the period "before the pandemic" do not fully realize their motivation, perhaps this is due to the fact that they do not fully understand their needs and the needs of others. Thus, we found that there are significant differences in all indicators.

The comparative analysis of the results according to the methodology "Self-assessment of manifestations of fear of success" (G.V.Turetskaya) revealed some differences presented in Table 4, the data obtained allow us to analyze the differences between codependent women in the studied periods.

Table 4. Features of the distribution of indicators manifestation of fear of success in women withdifferent levels ofcodependency

\begin{tabular}{|l|c|c|}
\hline \multicolumn{1}{|c|}{ Feature } & $\begin{array}{c}\text { \% of respondents in } \\
\text { the pre-pandemic } \\
\text { period }\end{array}$ & $\begin{array}{c}\text { \% of respondents } \\
\text { during "during a } \\
\text { pandemic" }\end{array}$ \\
\hline Testing time & February 2019 & September 2020 \\
\hline $\begin{array}{l}\text { Fear of not having enough family } \\
\text { time }\end{array}$ & 48 & 26 \\
\hline $\begin{array}{l}\text { Dissatisfaction wour } \\
\text { professional role }\end{array}$ & 7 & 29 \\
\hline Underestimating your professional & 21 & 9 \\
\hline Fear of keeping the family relationsh & 19 & 5 \\
\hline $\begin{array}{l}\text { Refusal to further advance in } \\
\text { business }\end{array}$ & 17 & 9 \\
\hline
\end{tabular}




\begin{tabular}{|l|c|c|}
\hline Fear of a leadership position & 10 & 8 \\
\hline Loss of femininity & 6 & 8 \\
\hline
\end{tabular}

As a result of studying the main manifestations of fear of success among women, we found that the majority of respondents experience significant anxiety about the insufficient time and attention given to their family or loved ones. Significant differences were found for this indicator between codependent women during the period "during the pandemic" (48\%) and codependent women during the period "before the pandemic" (26\%).Codependent women in the period "during a pandemic" find it difficult to allocate their own resources, therefore, in the process of achieving success, building their own career, they have a fear of lack of time and the feeling that they are taking this time away from their loved ones. Often the partners of codependent women indicate to them that they are not receiving enough attention, but this does not always reflect reality.

Codependent women in the period "before the pandemic" more often feel fear of being dissatisfied with their professional role $(29 \%)$. Perhaps women with a normal level of codependency are afraid to no longer realize themselves in the profession, as they are more focused on career success.

Codependent women during the "pandemic" period are more than twice as likely to underestimate their professional achievements than codependent women during the "prepandemic" period $(21 \%$ and $9 \%$, respectively) underestimate their professional achievements. For codependent women during an emergency, their professional achievements are not important, especially if they are not assessed by a partner. Codependents appreciate the assessment of others, they are accustomed to the fact that their actions are dictated from outside and are not always guided by their desires.

At the same time, $19 \%$ of codependent women during the "pandemic" period and only $9 \%$ of codependent women during the "pre-pandemic" period are afraid of preserving their family and personal relationships. Perhaps this is due to the fact that codependent women simply do not represent themselves outside the family, therefore they feel fear.

Significant differences were found in terms of the fear indicator "refusal to move forward in business"; in codependent women during the period "during a pandemic", this fear occurs three times more often than in Codependent women during the period "before the pandemic" (17\% and 5\% respectively). Codependent women are ready to give up their position and any advancement.

No significant differences were found in terms of "fear of leadership positions" and "loss of femininity," so in both samples these fears are rather rare.

Thus, we can conclude that for codependent women during the period "during a pandemic", an increase in fear of lack of time, underestimation of their professional achievements, fear of preserving the family, as well as refusal to further advance is characteristic.

\section{Discussion}

Due attention is paid to the problems of success in psychological science. It is considered from various theoretical positions and is studied in foreign science by such scientists as: S. Bandura, A. Maslow, K. Levin, D. Kuhn, 1. Monahan, F. Salili, P. Shaver, K. Shibe and others [3]. Many researchers, considering "success" from a phenomenological point of view, say that it is originally embedded in the structure of human existence. McClelland in his works said that a person who is oriented towards success takes calculated risks. Such people do not prefer easy tasks, because they do not feel that they will bring them success, however, they do not set themselves difficult tasks, realizing that they can lead to failure. Highlighting the criteria for success, we see the following division into external and 
internal, the first refers to the visible achievements of a person, the second refers to the inner world of a person and how the achievement of the goal affects him.

However, people in codependent relationships tend to lack the necessary skills, resulting in dysfunctional relationships and ineffective functioning. Codependency is a certain transformation of the value-semantic sphere of the individual, conditioned by stable learned patterns of behavior in interaction with significant others, mediating the attitude towards oneself and all other relationships [2, 6, 9]. Thus, codependency, being an adaptation to significant life events, includes subsequent profound transformations of the value-semantic sphere of the individual in the form of: a change in attitude towards a significant other and towards oneself personally; restructuring of life goals and value orientations under the influence of a significant other; distribution of responsibility for oneself and the life of another. $[11,16,19,20]$. Thus, we see that both the concept of "codependency" and the concept of "success" are based on the semantic sphere of the personality. At the same time, our study has demonstrated that despite the fact that the manifestation of the levels of codependency is static in an emergency situation (COVID-19 pandemic), the ideas of success among codependent women are quite labile.

\section{Conclusions}

Our study is an attempt to identify the features of the perceptions of success among codependent women in the period "before the pandemic" and during the COVID-19 pandemic:

1. In our sample, moderately pronounced codependency is most pronounced in $42 \%$ of women. $30 \%$ of the women surveyed have a normal level of codependency. They know how to adequately assess their relationships with other people. The least pronounced codependency in the total sample is observed, observed in $28 \%$ of women. These women show a strong physical, emotional and physical dependence on the object of the codependent relationship. For the pronounced differences in the ideas of success among codependent women in the period "before the pandemic" and during the emergency, we investigated the subgroup "Pronounced codependency".

2. The carried out correlation analysis showed:the level of codependency of women in the period "during a pandemic" is associated with the fear of not having enough time devoted to the family $(\mathrm{r}=0.56$, at $\mathrm{p} \leq 0.05)$, with the fear of preserving the family $(\mathrm{r}=0.53$, at $\mathrm{p} \leq 0.05$ ) and with fear of a leadership position $(\mathrm{r}=0.65$, at $\mathrm{p} \leq 0.05)$. We found a relationship between the manifestation of codependency in women during a pandemic and an orientation toward failure $(\mathrm{r}=0.48$, at $\mathrm{p} \leq 0.05)$. Desire to avoid failure and anynegative consequences provokes women to achieve, but there is no self-confidence.There is a relationship between pre-pandemic level of codependency in women and women's perceptions of success. The level of manifestation of codependency in women during the period "before the pandemic" has an inverse relationship associated with the fear of not having enough time devoted to the family $(\mathrm{r}=-0.65$, at $\mathrm{p} \leq 0.05)$ and with the fear of a leadership position $(\mathrm{r}=-0.51$, at $\mathrm{p} \leq 0.05)$. The revealed direct correlation relationship between their level of codependency and dissatisfaction with their professional role $(\mathrm{r}=$ 0.48 , at $\mathrm{p} \leq 0.05$ ) indicates that the higher the level of codependency among women in the period "before the pandemic", the higher the fear of not to be realized in the profession. We found a relationship between the level of codependency and orientation towards success $(\mathrm{r}$ $=0.45$, at $\mathrm{p} \leq 0.05$ ). The more codependent women in the pre-pandemic period are oriented towards success, the less they exhibit codependent behavior. 


\section{References}

1. I. Abakumova, L. Kruteleva, E. Ryadinskaya, Transformation of Life-Sense Strategies of a Person in the Armed Conflict Environment: Theoretical Research, 6thWorld Congress of Psychology and Behavioral Sciences (Management, Psychology, Political and Social Sciences) (WCPBS 2016), Universitat Barcelona, 1-6. (2016).

2. M. Beattie, Beyond Codependency and getting better all the time (Harper\&Row, SanFrancisco, 1989).

3. R.F. Bornstein, American Psychologist. September 61 (6), 595-606 (2006). http://dx.doi.org/10.1037/0003-066X.61.6.595

4. J.A. Fuller, R.M. Warner, Family stressors as predictors of codependency, Genetic, social, and general psychology monographs 126 (1), 5-22 (2000).

5. S. Karpman, A Game Free Life (Self Published, San Francisco, 2014).

6. E. Larsen, Stage II Recover: Life Beyond Addiction (Harper\&Row, San Francisco, 1985).

7. C. McMillen, S. Zuravin, G. Rideout, Journal of Consulting and Clinical Psychology 63 (4), 1037-1043 (1995).

8. W. Mendenhall, CourseonCo-dependence (NJ, New Brunswick, 1987).

9. P. Mellody, Facing Love Addiction: Giving Yourself the Power to Change the Way You Love (Hazelden Publishing, Wickenburg, 2003).

10. S. Sarkar, S.K. Mattoo, D. Basu, J. Gupta, International Journal of Culture and Mental Health 8 (1), 13-21 (2015). https://doi.org/10.1080/17542863.2013.868502

11. A.W. Schaef, Co-DependenceMisunderstood-Mistreated (Harper\&Row, New York, 1986).

12. M. Shafer, Psychoter. Psychosom. Med. Psychol. 50 (2), 38-50 (2000).

13. R. Subby, J. Friel, Co-dependency: A Paradoxica Dependency in Co-Dependency: An Emerging Issue. Pompano Beach, FL: Health Communications, 1984.

14. Y. Ulusoy, S.S. Guçray, Journal of International Social Research 10 (49) (2017).

15. F.E. Vasilyuk, Journal of Russian \& East European Psychology 52 (1), 1-58 (2015).

16. S. Wegscheider-Cruse, Choicemaking: For Co-dependents, Adult Children And Spirituality Seekers, Health Communications, Pompano Beach, FL, 1985).

17. M.C. Wells, M.B. Hill, G. Brack, C.J. Brack, E.E. Firestone, Journal of College Student Psychotherapy 20 (4), 71-84 (2006).

18. C.L. Whitefield, Alcohol. Treat. Quart. 6 (1), 19-36 (1989).

19. C.L. Whitfield, Codependence: Healing the Human Condition: The New Paradigm For Helping Professionals And People In Recovery, Health Communications, Deerfield Beach, FL, 1991.

20. E. Young, J. Psychoactive Drugs 19 (3), 257-268 (1987).

21. U. Zetterlind, M. Berglund, Nordic Journal of Psychiatry 53 (2), 147-151 (1999). 